\title{
ANÁLISE DE ESTRATÉGIAS DE ESTUDO DIVULGADAS NO YOUTUBE
}

\author{
ANALYSIS OF STUDY STRATEGIES DISCLOSED ON YOUTUBE \\ ANÁLISIS DE LAS ESTRATEGIAS DE ESTUDIO REVELADAS EN YOUTUBE
}

Tenisziara Moura Ferreira

E-mail: tenisziara.ferreira@gmail.com

\author{
Beatriz Gaydeczka \\ E-mail: beatriz.gaydeczka@uftm.edu.br \\ Universidade Federal do Triângulo Mineiro - UFTM
}

\begin{abstract}
RESUMO
Este artigo traz resultados de uma pesquisa que objetivou identificar as estratégias de estudo utilizadas e recomendadas por estudantes no YouTube. Para isso, foram selecionados 50 vídeos do YouTube, a partir da tabulação dos conteúdos temáticos mais recorrentes, identificaram-se as estratégias que foram organizadas e agrupadas em seis categorias: a) estudo individual; b) organização para os estudos; c) interação; d) comportamento durante as aulas; e) bem estar físico e mental e f) preparação para as avaliações. O resultado evidenciou que os estudantes YouTubers apresentaram conhecimento superficial e empírico sobre estratégias de estudo. Suas estratégias estão baseadas em experiências pessoais por tentativa e erro. Assim, observa-se a necessidade de mais pesquisas referentes à temática, no sentido de contribuir na orientação aos estudantes desde os anos iniciais da vida escolar até a educação superior.
\end{abstract}

PALAVRAS-CHAVE: Concepções de aprendizagem. Desempenho Acadêmico. Educação Superior. YouTube.

\section{ABSTRACT}

This paper presents the results of a research that aimed to identify the study strategies applied and recommended by students on YouTube videos. For this, 50 YouTube videos were selected, based on the tabulation of the most recurring thematic content, the strategies were identified and were organized and grouped into six categories: a) individual study; b) organization for study; c) interaction; d) behavior during the classes; e) physical and mental well-being andf) preparation for evaluations. The result evidenced that the students who are Youtubers presented superficial and empirical knowledge regarding the study strategies. Their strategies are based on personal experiences, by trial and error. Thus, it is observed the need of research on this subject, in order to contribute in guiding students from the early years of school life until higher education.

KEYWORDS: Learning conceptions. Performance. Higher education. YouTube.

\section{RESUMEN}

Este artículo presenta los resultados de una investigación que tuvo como objetivo identificar las estrategias de estudio aplicadas y recomendadas por los estudiantes en los videos de YouTube. Para esto, se seleccionaron 50 videos de YouTube, basados en la tabulación del contenido temático más recurrente, se identificaron las estrategias y se organizaron y agruparon en seis categorías: a) estudio individual; b) organización para el estudio; c) interacción; d) comportamiento durante las clases; e) bienestar físico y mental y f) preparación para evaluaciones. El resultado evidenció que los estudiantes que son Youtubers presentaron conocimiento superficial y empírico con respecto a las estrategias de estudio. Sus estrategias se basan en experiencias personales, por ensayo y error. Por lo tanto, se observa la necesidad de investigar sobre este tema, con el fin de contribuir a guiar a los estudiantes desde los primeros años de la vida escolar hasta la educación superior.

PALABRAS-CLAVE: Concepciones de aprendizaje. Actuación. Educación más alta. Youtube. 


\section{INTRODUÇÃO}

O ensino superior é um nível de formação que exige maturidade, proatividade e autonomia estudantil. No entanto, muitos estudantes chegam a essa etapa de formação com percepções superficiais dessas características e necessidades, das responsabilidades sobre sua aprendizagem e pouco conhecimento sobre estratégias de estudo que podem contribuir para um desempenho acadêmico satisfatório, do ponto de vista das competências a serem desenvolvidas para os egressos de cursos superiores.

Acreditamos que o ensino de estratégias de estudo aos alunos, desde os anos iniciais da educação básica até a superior, pode promover relativa autonomia e aumentar sua capacidade de autorregulação, colaborando positivamente para a aprendizagem significativa dos estudantes (TEIXEIRA; ALLIPRANDINI, 2013; HAUGEN, 2015).

No que se refere a publicações digitais que se dedicam à temática "estratégias de estudo para a aprendizagem no ensino superior", observou-se que há pouca produção a respeito. Num levantamento feito em cinco repositórios digitais (SCIELO, BDTD, ERIC, SCIENCE DIRECT e PUBMED)i, foram identificadas apenas 403 publicações relacionadas ao tema. Após triagem, avaliando os títulos e os resumos, somente $16^{\mathrm{ii}}$ tratavam, especificamente, de estratégias de estudo enfocando aprendizagem na educação/ensino superior. Isso sinaliza a necessidade de pesquisas voltadas ao desenvolvimento de estratégias de estudo, a fim de contribuir para a melhoria da aprendizagem significativa dos estudantes. Ao final deste artigo é apresentado um quadro com listagem das publicações identificadas.

O presente artigo tem foco na aprendizagem dos estudantes, a partir das seguintes indagações: "como" ou "o que os estudantes do ensino superior fazem para estudar e aprender?"

Para responder a essas indagações, vídeos do YouTube foram selecionados como objeto de estudo e base de dados. Partiu-se do pressuposto que, nesse ambiente, seria possível identificar um conjunto de vídeos que tratassem de estratégias de estudo desenvolvidas pelos próprios estudantes, em especial, aqueles que se consideram "de sucesso", com êxito nos estudos. Assim, foi possível identificar indícios representativos do perfil de estudante do ensino superior, das concepções de estudo, bem como das práticas de ensino-aprendizagem desenvolvidas nas instituições educativas. 


\section{ESTRATÉGIAS DE ESTUDO: O APRENDER A APRENDER}

Aprender a aprender é uma expressão polêmica no mundo acadêmico. Ela revela o protagonismo do estudante e a competência de estar preparado para mudanças e atualizações do mundo contemporâneo. "O único homem que se educa é aquele que aprendeu como aprender; que aprendeu como se adaptar e mudar; que se capacitou de que nenhum conhecimento é seguro" (ROGERS, 1973, p. 104). Assim, é preciso transcender o papel de aluno e assumir as responsabilidades como estudante, fazer-se um profissional do estudo com planejamento, estratégias fundamentadas e compromisso cotidiano (PIAZZI, 2013).

De acordo com Haugem (2015), as "estratégias de estudo" são maneiras específicas de pensar e agir em relação ao conhecimento escolar. Acredita-se que essas estratégias podem ensinadas e praticadas. Por falta de preparo, muitos estudantes costumam utilizar estratégias de estudo superficiais, qualitativa e quantitativamente ineficientes, que tendem a ser influenciados pelo tipo de aula que vivenciam e pela dinâmica curricular que orienta a ação pedagógica nos cursos frequentados (GALVÃO; CÂMARA; JORDÃO, 2012).

Cabe destacar que, nesse contexto, a aula é apenas uma das etapas do processo de aprendizagem. Piazzi (2013) explica que, durante as aulas, o estudante entende o conteúdo que está sendo ensinado e essa informação fica armazenada na memória de curto prazo. Para que a aprendizagem seja efetiva, os conteúdos sejam apropriados e as habilidades e competências sejam desenvolvidas, são necessárias atividades que garantam ações participativas e autorais do estudante.

Nesse processo, o professor exerce papel como mediador e facilitador da aprendizagem. Contudo, há que se pensar na formação desse profissional, no sentido de preparar os estudantes quanto ao uso de estratégias de estudo. Da mesma forma que o professor utiliza métodos de ensino, o aluno precisa utilizar as estratégias de estudo para auxiliar a aprendizagem.

Desenvolver estratégias eficientes de estudo parte desde a organização prévia, cuidados com a saúde e outros fatores influenciadores, até o ato efetivo de estudar. Assim, aprender, neste contexto, não se trata da reprodução automática e passiva de informações para as provas. É preciso que haja um processamento dessas informações por meio de análises, questionamentos e pesquisas que oportunizem a construção de conhecimentos consistentes e desenvolvimento de competências, por meio da vivência de conhecimentos, habilidades e atitudes. 


\section{UMA SÍNTESE DAS TEORIAS E CONCEPÇÕES DE APRENDIZAGEM}

As teorias de aprendizagem estão inseridas no ramo da psicologia em educação, que busca entender os processos de construção do conhecimento do ser humano. São tentativas humanas de interpretar sistematicamente a área do conhecimento denominada aprendizagem (MOREIRA, 1999).

A literatura é vasta e seus pensadores trouxeram grandes contribuições à educação e ao processo de aprendizagem. Numa perspectiva histórica as tendências das teorias de aprendizagem partiram de abordagens mais comportamentalistas, perpassando as cognitivistas, construtivistas, interacionistas e chegando às mais humanistas. Pesquisadores como Skinner, Piaget, Vigotsky, Ausubel, Rogers, Gardner e Freire apresentaram destaque.

Quadro 1: As principais correntes teóricas de acordo com Moreira (1999)

\begin{tabular}{|l|l|}
\hline Comportamentalismo & $\begin{array}{l}\text { Seus conceitos-chave são: estímulo-resposta, condicionamento, } \\
\text { reforço, objetivo-comportamental. Os idealizadores de destaque } \\
\text { Pavlov, Watson, Guthrie e Skinner. }\end{array}$ \\
\hline Cognitivismo & $\begin{array}{l}\text { Seus conceitos-chave são: esquema, signo, modelo mental, } \\
\text { subsunçor } \\
\text { Destacaram-se construto pessoal, zona de desenvolvimento proximal. }\end{array}$ \\
\hline Humanismo & $\begin{array}{l}\text { Tendo como pioneiro Rogers, que difundiu conceitos-chave como } \\
\text { aprender a aprender, liberdade para aprender, ensino centrado no } \\
\text { aluno e crescimento pessoal. }\end{array}$ \\
\hline
\end{tabular}

Cada teoria possui características intrínsecas. A formação e os interesses dos idealizadores, o contexto de construção da teoria, a forma de sistematização e o momento histórico influenciaram sua gênese e epistemologia. Em alguns casos, uma teoria influenciou o desenvolvimento de outra. Por exemplo, Vigotsky discordava da teoria de Piaget ${ }^{\mathrm{i}}$. Em outros casos, os termos se modificam, mas o sentido é similar. Por exemplo, o "organizador prévio" de Ausubel e a "zona de desenvolvimento proximal" de Vigotsky. Embora raramente o constructo teórico tenha sido desenvolvido pensando no contexto de aplicação, cada teoria encontra sua relação com os aspectos preconizados em processos educativos, tais como a 
cognição, a metacognição, o desenvolvimento, o pensamento, a aprendizagem, a linguagem, entre outros.

\section{SÍNTESE DO PROCESSO DE APRENDIZAGEM SEGUNDO GAGNÉ E AUSUBEL}

A teoria das hierarquias de aprendizagem de Gagné (1980) tem como base o processamento de informações, evoluindo de uma perspectiva behaviorista para outra, predominantemente, cognitivista. Nessa perspectiva, aprendizagem é uma mudança comportamental persistente observável, advinda de estimulações do ambiente externo.

De acordo com Moreira (1999, p. 67), "esse modelo propõe que o 'fluxo de informação' afeta os 'receptores' do aprendiz e entra no sistema nervoso através de um 'registrador sensorial" ". Após ser considerada no "registrador sensorial", a informação sofre nova codificação ao entrar na "memória de curta duração". A permanência na "memória de curta duração" é relativamente breve, da ordem de segundos, de modo que, se a informação é para ser lembrada, ela deve ser novamente transformada e entrar "na memória de longa duração". A informação proveniente, tanto da "memória de breve duração" quanto da de "longa duração", passa para um "gerador de resposta" que tem a função de transformar a informação em ação.

Gagné (1980) também desenvolveu o entendimento do ciclo de aprendizagem, que se constitui pela motivação (fase preparatória para a aprendizagem); apreensão (prestar atenção e observar atentamente o que está sendo estudado); aquisição (quando a informação recebida entra na memória de curta duração por meio da codificação); retenção (armazenamento na memória); rememoração (recuperação da informação que foi codificada e armazenada na memória de curto prazo); generalização (quando a informação é transferida da memória de curto prazo para a de longo prazo e espera-se que o aprendiz seja capaz de usar o que foi aprendido em contextos diferentes); desempenho (ocorre a resposta do estudante); retroalimentação (quando o professor é capaz de observar mudanças no comportamento do aprendiz) e reforço (fechamento do ciclo de aprendizagem).

Já Ausubel (2006), distingue três tipos gerais de aprendizagem: cognitiva (que resulta do armazenamento organizado de informações na mente do ser que aprende), afetiva (que pode ser identificada como experiências de prazer, dor, satisfação, descontentamento, alegria, ansiedade) e psicomotora (respostas musculares adquiridas por meio de treino e prática). 
Ausubel focaliza seu trabalho na aprendizagem cognitiva. Para ele, "aprendizagem significa organização e integração do material na estrutura cognitiva” (MOREIRA, 1999, p. 152). Nesse contexto, o que o aluno já sabe é o que mais influencia a aprendizagem. Sua teoria é denominada Teoria das Aprendizagens Significativas:

(...) um processo por meio do qual uma nova informação relaciona-se com um aspecto especificamente relevante da estrutura de conhecimento do indivíduo, ou seja, este processo envolve a interação da nova informação com uma estrutura de conhecimento específica, a qual denomina conceito subsunçor (MOREIRA, 1999, p. 153).

Para Ausubel (2006), a aprendizagem só é significativa se o conteúdo descoberto se ligar a conceitos subsunçores relevantes, já existentes na estrutura cognitiva.

Ausubel desenvolveu e classificou a aprendizagem em três categorias: aprendizagem subordinada (a nova informação adquire significado por meio da interação com subsunçores, o que reflete uma relação de subordinação em relação aos conhecimentos preexistentes); aprendizagem superordenada (quando a informação nova é ampla demais para ser assimilada por qualquer subsunçor existente, sendo mais abrangente que esses) e a aprendizagem combinatória (aprendizagem de proposições) (MOREIRA, 1999).

Essa base teórica que busca fundamentar que processos de aprendizagem são relevantes na medida em que o estudante os compreende, incorpora e está disposto a usar de maneira adequada ao ingressar no ensino superior bem como em sua vida. Dessa forma, buscouse identificar as estratégias de estudo utilizadas e recomendadas por estudantes no YouTube. A partir disso, foi possível identificar indícios representativos do perfil de estudante do ensino superior, das suas concepções de estudo, bem como das práticas de ensino-aprendizagem desenvolvidas nas instituições educativas.

\section{PROCEDIMENTOS METODOLÓGICOS}

Conforme dito, o objeto de estudo desta pesquisa são vídeos publicados no YouTube contendo depoimentos de estudantes sobre as estratégias consideradas mais eficientes no ato de estudar. Assim, trata-se de uma pesquisa qualitativa, na qual foram realizados os seguintes passos:

a. construção do corpus, constituído por 50 vídeos do YouTube, selecionados a partir da expressão "como eu estudo" no mecanismo de busca da plataforma. Em um primeiro 
levantamento (realizado em 05/10/2016), foram identificados 44.300 vídeos. Os critérios de inclusão e de recorte do corpus foram: vídeos relacionados com as palavras-chave "como eu estudo"; brasileiros; em português; publicados em 2016; do tipo vídeo; classificados por relevância (ou seja, os mais visualizados).

b. identificação, agrupamento e quantificação em categorias dos tópicos recorrentes nos 50 vídeos;

c. análise de conteúdo, relacionando os tópicos mais frequentes às tendências ou às abordagens das teorias de aprendizagens, conforme Bardin (2010).

d. descrição das estratégias mais e menos recorrentes.

\section{RESULTADOS E DISCUSSÕES}

Fazendo um levantamento geral da amostra, foram analisados 50 vídeos, num total de cinco horas e cinquenta e nove minutos de gravação. Dos vídeos analisados, 40 foram publicados por pessoas do sexo feminino; 9 do sexo masculino e 1 não identificado o gênero. Desses, 8 apresentavam aparência de criança, 17 de adolescente, 24 de adulto e 1 não identificado o perfil de idade, dado apenas observado, pois o YouTube não divulga esse tipo de informação.

Com relação ao ambiente de gravação, ou seja, os espaços em que foram filmados os vídeos: 25 foram na sala de casa; 23 no quarto e 2 em estúdio. Foram observados aspectos relacionados à modalidade ou ao nível escolar a que os vídeos eram dedicados (Tabela 1). Essas informações foram depreendidas por meio da contextualização, referenciação e dedução das pistas textuais:

Tabela 1: Modalidade ou nível escolar a que os vídeos eram dedicados

\begin{tabular}{|l|c|}
\hline Modalidade & Quantidade de vídeos \\
\hline Estudantes do ensino fundamental e médio & 18 \\
\hline Estudantes em geral & 10 \\
\hline Universitários & 6 \\
\hline Estudantes de concursos & 6 \\
\hline Público religioso & 5 \\
\hline Vestibulandos & 4 \\
\hline Estudante de música & 1 \\
\hline Total & 50 \\
\hline
\end{tabular}

Fonte: Das autoras, 2020 
As estratégias de estudo identificadas foram agrupadas em seis categorias, sendo elas:

- "Estudo individual” com 57 estratégias de estudo;

- “Organização para os estudos” com 26 estratégias de estudo;

- "Interação" com 13 estratégias de estudo;

- “Comportamento durante as aulas" com 9 estratégias de estudo;

- "Bem-estar físico e mental” com 8 estratégias de estudo;

- "Preparação para avaliações” com 5 estratégias de estudos.

\section{a) Categoria "Estudo individual"}

Nessa categoria foram identificadas 57 estratégias. Dessas, 34\% recomendam "utilizar caderno de resumos", quase $20 \%$ recomendam o uso de marca texto, $16 \%$ recomendam estudar escrevendo e 16\% sugerem estudar diariamente. Dunlosky et al. (2013) explicam que tópicos estes citados exercem grande influência na aprendizagem, como é o caso de "ler e tentar compreender", "levantar questionamentos sobre o texto e tentar responder".

A respeito da produção de resumos, cabe destacar que se o aluno entende "a produção de resumo" como cópia de trechos considerados importantes, essa estratégia é de baixa utilidade porque é superficial e repetitiva, o que não significa que haja compreensão, apreensão de sentidos e aplicação/uso efetivamente, tal como pressupõe a finalidade de escrita de resumos. A seleção e a paráfrase de informações devem beneficiar mais a apreensão de significados do que simplesmente ler um texto destacando com marca texto. Porém, se "a produção de resumo" é entendida e realizada como síntese (com articulação dos conceitos; exclusão de repetições; capacidade de síntese e de paráfrase do conteúdo), nessa perspectiva, a produção de resumos revela-se uma estratégia significativamente importante.

Algumas estratégias citadas pelos estudantes YouTubers exercem grande influência na aprendizagem, como é o caso de ler e tentar compreender, levantar questionamentos sobre o texto e tentar responder. Essas estratégias tiveram eficiência comprovada na pesquisa de Dunlosky et al. (2013). Já a simples releitura foi classificada como de baixa utilidade, embora tenham sido comprovados vários benefícios na utilização dela. Isto se deve à quantidade insuficiente de pesquisas que examinaram sistematicamente até que ponto os efeitos de releitura dependem de outras características dos alunos, como conhecimento ou habilidade prévia. 
Dentre as sugestões de "estudo individual" menos frequentes, foram apresentadas sugestões de estratégias condizentes com o que preconizam as concepções interacionistas e humanistas, tais como:

\footnotetext{
"Não há uma única forma de estudar, cada um aprende de um jeito."

"Procurar ver a aplicação dos conteúdos no dia a dia."

"Procurar curiosidades sobre os conteúdos que estão sendo estudados."

"Ler sobre o assunto antes da aula."

"Levantar questionamentos sobre o texto e tentar responder."

"Fazer resumo dos conteúdos que encontrou mais dificuldades."
}

Como se pode observar, essas estratégias dependem da consciência da maneira mais adequada para apreender o conhecimento; da aplicação, pois pode envolver habilidades de empregar o que foi aprendido no dia a dia (profissional ou pessoal); de preparar-se para aprender os conteúdos, temas e assuntos a serem trabalhos em sala de aula; de tentar superar dificuldades, questionar o que está sendo estudado. Essas estratégias, apesar de mencionadas apenas uma vez, revelam que a aprendizagem depende muito mais da proatividade, da motivação e do empenho do estudante em querer aprender.

Além disso, tal como destaca Almeida (2016), cabe considerar que cada estudante possui particularidades específicas, conforme explica a teoria de Ausubel. Assim, não há como afirmar se determinada estratégia será ou não eficiente para todos e/ou para todas as áreas do conhecimento. De acordo com Dunlosky et al. (2013), o aprendizado é possível a partir da compreensão geral de um conteúdo, da seleção dos itens importantes, da elaboração desses itens pelo estudante e da testagem dessa elaboração. Cada estratégia utilizada é apenas uma etapa desse processo. Estratégias de estudo são ferramentas de aprendizagem que cada estudante precisa conhecer, experimentar e selecionar as que melhor se adaptam à sua realidade. Assim, primeiramente, é necessário identificar a realidade, o conteúdo e o objetivo do estudo para, então, escolher as estratégias que serão utilizadas.

\section{b) Categoria "Organização para os estudos"}

Nessa categoria, 22\% dos estudantes YouTubers consideram importante "Ter um cronograma de estudos", 20\% recomendam "utilizar agenda física ou digital para se organizar" e $8 \%$ orientam "Buscar ser organizado". Também foram citadas as seguintes estratégias: "Fazer 
pequenos intervalos entre os períodos de estudo"; "Dedicar mais tempo de estudo aos conteúdos que possuem mais dificuldade em aprender"; "Estudar até uma hora seguida cada disciplina. Não mais"; "Mesclar conteúdos de humanas com conteúdos de exatas"; "Prever sempre meia hora a mais para cada período de estudo devido às pausas"; "Intercalar conteúdos mais difíceis com conteúdos mais fáceis" e "Procurar fazer coisas que descansem o cérebro durante as pausas".

Outras questões que envolvem a organização, porém, do ambiente de estudos são "Procurar um ambiente adequado para estudar", "Não estudar no sofá, na cama, etc.”, "Procurar estudar em ambientes com pouca poluição visual", "Deixar tudo que irá precisar perto de si, evitando ter que interromper os estudos para buscá-los".

De acordo com Alves (2014), a poluição visual se dá quando as informações visuais estão em excesso ou algum fator que cause algum estresse estético no ambiente que afeta a qualidade de vida dos seres humanos. A sua exposição prolongada afeta a saúde humana provocando desconforto visual, estresse e até transtornos a saúde mental.

Galvão, Câmara e Jordão (2012) afirmam que a aprendizagem se beneficia mais da prática distribuída do que da prática concentrada. Intervalos prolongados de descanso seguidos de sessões curtas de estudo são mais eficientes para a aprendizagem. As pausas e os revezamentos de conteúdos podem ser positivos, bem como o foco em conteúdos de maiores dificuldades. Aprender efetivamente exige tempo para o amadurecimento das ideias.

Ainda de acordo com os dados, o estudante desorganizado pode se perder ou esquecer de coisas importantes na rotina de estudo. A organização o ajuda a manter o foco no que está sendo estudado. A desorganização pode desencadear distração e procrastinação. Uma boa gestão do tempo e dos materiais auxiliam no estabelecimento de rotinas de estudo, com maior economia de tempo, evitando prejuízos na vida acadêmica.

Estudantes procrastinadores tendem a não resistir a distratores (redes sociais, Internet, TV), sendo mais propensos a substituir a execução de tarefas acadêmicas por alternativas mais atrativas e que oferecem retorno imediato, como ocorre com o uso de redes sociais. De modo geral, a procrastinação é um fenômeno relativamente comum entre os estudantes, sendo, geralmente, tido como prejudicial à vida acadêmica (SCHOUWENBURG, 2004 apud SAMPAIO et al., 2012). Pesquisas recentes têm compreendido a procrastinação como uma falha no processo de autorregulação da aprendizagem (SAMPAIO et al., 2012). À medida que o indivíduo autorregula sua aprendizagem com eficiência, tende a procrastinar menos. 


\section{c) Categoria "Interação"}

Nessa categoria foi possível observar interações entre o estudante e as tecnologias digitais; o estudante e o professor; e, o estudante e outros estudantes. No que se refere à relação do estudante com as tecnologias digitais, enquanto alguns apresentam aspectos negativos dessa interação, outros apresentam o uso da Internet como uma ferramenta positiva para a aprendizagem.

Dos vídeos analisados, uma parte acredita que tirar dúvidas na Internet é uma estratégia eficiente. Por outro lado, alguns acreditam que o uso de celular, Internet, televisão e redes sociais durante os períodos de estudo é prejudicial, porque atrapalha a concentração. "Explicar para alguém ou para si mesmo em frente ao espelho o que estudou" e "Participar de grupos de estudo" foi citado como positivo.

Segundo a teoria de Vigotsky (1998), o desenvolvimento cognitivo do aluno acontece por meio da interação social, ou seja, sua interação com outros indivíduos e com o meio. Explicar o conteúdo estudado para alguém ou para si mesmo, uma das estratégias citadas pelos estudantes YouTubers, evidenciou nos estudos de Dunlosky et al. (2013) como de eficiência moderada. A autoexplicação pode melhorar a aprendizagem, apoiando a integração de novas informações com o conhecimento prévio existente. Aparentemente, a maioria dos estudantes podem se beneficiar da autoexplicação com prática mínima. Afinal, de acordo com a teoria de Vigotsky (1998), é o pensamento verbal que nos ajuda a organizar a realidade em que vivemos. Demo (2008) considera importante o estudo em grupo, porém acredita que, para que seja efetivo, é necessário que cada integrante estude o conteúdo com antecedência e que, posteriormente, cada um desenvolva seu próprio material, além do construído pelo grupo.

Os estudantes YouTubers evidenciaram a interação do jovem com a Internet e as redes de comunicação difundidas na atualidade, confirmando que a sala de aula física já não é o único meio de se obter informações ou construir aprendizagens. Muitos estudantes já reconhecem a Internet como uma alternativa de ambiente de aprendizagem. De modo geral, observa-se que há uma dualidade no uso de tecnologias digitais para os estudos. Trata-se de ferramentas que podem ser benéficas para as atividades de estudo se bem utilizadas e prejudiciais se não houver um direcionamento e autorregulação. 
d) Categoria "Comportamento dos estudantes durante as aulas"

Nessa categoria os estudantes recomendam "Gravar as aulas do professor para ouvir no momento do estudo individual"; "Tirar fotos dos slides do professor e organizar em pastas digitais"; "Imprimir os slides do professor".

Um dos momentos mais comuns na vida estudantil é a aula. Essa seria a fase da apreensão do Ciclo de Aprendizagem de Gagné. É quando se deve prestar atenção e observar atentamente o que está sendo estudado. Durante as aulas o estudante tem a oportunidade de socializar o novo conhecimento, tirar dúvidas, debater e amadurecer ideias. Dessa forma, prestar atenção ao que está sendo explicado pelo professor é a alavanca para aprofundar-se posteriormente. Embora a aula não seja o único momento de aprendizagem disponível, a participação durante elas e a autoria na construção de materiais, a partir das atividades e explicações do professor, podem ser decisivos para a aprendizagem. Fazendo isso, terá concluído a fase da aquisição, quando, segundo Gagné, a informação recebida entra na memória de curta duração por meio da codificação.

Após esse primeiro contato com o novo conteúdo, o estudante precisará se dedicar utilizando outras estratégias, a fim de que haja a retenção de Gagné, ou seja, o armazenamento na memória. Estudar fazendo anotações, por exemplo, é uma estratégia tida como bastante eficiente (GALVÃO; CÂMARA; JORDÃO, 2012). Sabe-se que uma das funções da escrita é organizar e sistematizar o pensamento, isso pode fazer sentido quando se trata de estratégia de estudo. Pesquisa realizada por Galvão (1999) comprovou as implicações dessa teoria para a aprendizagem, ao demonstrar que a leitura de textos, fazendo anotações, reforça significantemente o traço de memória do conteúdo textual. Uma possível explicação para isso é que esta estratégia de aprendizagem envolve processamento ortográfico e fonológico, o que remete a domínios metalinguísticos e mnemônicos.

\section{e) Categoria "Bem-estar fisico e mental"}

Os tópicos relacionados a essa categoria evidenciam questões relativas à saúde, como qualidade do sono, alimentação e prática de atividades físicas afetam o desempenho do estudante. Podendo beneficiar ou prejudicar sua aprendizagem.

Nessa categoria, alguns dos vídeos indicam "Tomar água durante o período de estudo"; outros destacam "Ter uma alimentação saudável”; "Praticar atividade física regularmente" e "Observar o horário do dia que seu organismo reage melhor aos estudos". 
Em se tratando de estratégias de aprendizagem, um dos primeiros aspectos a se considerar é a predisposição do estudante em aprender. A saúde, o bem-estar e a qualidade de vida dos educando são fatores essenciais para promoção da aprendizagem. Não há aprendizagem efetiva se o estudante está cansado, adoentado ou medicalizado (ANDRADE SILVA, 2015).

\section{f) Categoria "Preparação para as avaliações"}

Nessa categoria $8 \%$ citaram que é necessário "Estudar para as provas com antecedência" e $6 \%$ acham importante "Resolver provas anteriores".

A partir dos resultados apresentados neste trabalho, pode-se observar que a maior parte dos estudantes YouTubers relatam que estudam com o objetivo de obterem sucesso nas avaliações, mesmo que não tenham, de fato, construído um conhecimento significativo a respeito daquilo que será avaliado.

Conforme já citado, estudar cotidianamente, homeopaticamente e constantemente é mais efetivo que estudar intensamente em um curto espaço de tempo. Se o estudante tem como objetivo o verdadeiro aprendizado, demandará tempo para que ocorra o amadurecimento do conhecimento. Por esse motivo, se as avaliações são necessárias, é importante estudar e revisar constantemente os temas as serem estudados.

Pesquisa realizada nos Estados Unidos, por Dunlosky et al. (2013), avaliou centenas de estudos científicos que investigaram dez das estratégias de revisão mais populares e verificaram que oito delas não funcionam, ou mesmo, em alguns casos, atrapalham o aprendizado. A produção de resumos e a utilização de marca texto, muito citadas pelos estudantes YouTubers, foram classificadas pela pesquisa de Dunlosky como estratégias de baixa utilidade. Essas estratégias geralmente atraem estudantes porque são simples de usar. No entanto, fazem-se necessárias ações específicas, mapeadas, sintetizadas, aplicadas, socializadas, que, muitas vezes, os estudantes não dominam.

A forma, como os estudantes do YouTube percebem e utilizam as estratégias de estudo, pode evidenciar metodologias de ensino mais frequentemente desenvolvidas no país. O fato de muitos estudantes aplicarem determinadas estratégias não significa que haja comprovação científica sobre sua eficiência para a aprendizagem.

Tal como defendem Freire (2010), Ausubel (2006), Perrenoud (2014) dentre outros, o princípio para a efetiva aprendizagem, ou seja, aprendizagem em que o aprendiz seja capaz de 
usar o que foi aprendido em contextos diferentes, é a capacidade de ter autonomia e atitude. Faz-se necessário ser protagonista do processo, assumir tarefas em vez de receber tudo pronto, construir o novo a partir dos estudos, levantar hipóteses, questionamentos e, se possível, ensinar alguém ou socializar o apreendido.

\section{CONCLUSÃO}

De acordo com os resultados da pesquisa, verifica-se que as estratégias de estudo comumente utilizadas pelos estudantes dependem do modelo de ensino no qual estão inseridos e, portanto, a importância de que estratégias de estudo sejam ensinadas nas instituições formais de ensino desde os anos iniciais da vida escolar.

Observou-se certa confusão dos estudantes entre o conceito de "estratégias de estudo" e "organização para os estudos". Em muitos vídeos, os estudantes afirmavam que iriam discorrer sobre estratégias de estudo e acabavam abordando apenas estratégias de organização e planejamento para os estudos.

Embora, reunindo-se todos os depoimentos dos 50 vídeos, seja possível construir uma linearidade das estratégias de estudo para o processo de aprendizagem, de forma geral, ficou claro o conhecimento superficial e empírico da maioria dos estudantes a respeito do ato de estudar. Uma tendência à reprodução de estratégias comumente difundidas, bem como pouca ou nenhuma base técnica e científica na aplicabilidade dessas estratégias de estudo.

Estudar é uma prática milenar, porém, ainda são incipientes as investigações referentes à temática, o aprimoramento de estratégias, a verificação de aplicabilidade e o ensino delas em instituições da educação básica e superior. O que acarreta é a prática intuitiva por estudantes e professores. A depender da sorte, se o estudante desde o início se adaptar a determinadas estratégias, obterá bom desempenho por toda a sua trajetória escolar; do contrário, poderá obter resultados insatisfatórios até o ensino superior. Isso poderia ser evitado com intervenções desde os anos iniciais da escolarização, apresentando-lhe diferentes estratégias de estudo e testando alternativas.

Observou-se relativa consciência dos estudantes com relação à importância de ser organizado, cuidar da saúde física e mental, ser frequente e prestar atenção nas aulas, estudar regularmente e ser comprometido. No entanto, apresentam suas estratégias como conhecimentos intuitivos e acreditam que estes conhecimentos empíricos sejam conceitos, conselhos e dicas que podem servir para todos. 
Com esta pesquisa, verifica-se que as instituições de ensino possuem papel fundamental no sentido de orientar os estudantes sobre o uso das estratégias de estudo e de auxiliá-los no processo de autoconhecimento. Em alguns casos, são necessárias estratégias de memorização e, em outros, de compreensão e interpretação, de mapeamento, de síntese e de socialização. Primeiramente é necessário identificar a realidade do estudante, o conteúdo e o objetivo do estudo para, então, escolher as estratégias a serem recomendadas em cada fase do processo de aprendizagem.

Outra questão importante que a pesquisa evidenciou, que influencia no ato de aprender, é a bagagem de conhecimentos, hábitos e atitudes construídos sócio historicamente pelo estudante, uma vez que funciona como referência para novas associações, conforme descreve a teoria das aprendizagens significativas de Ausubel.

No que confere ao ensino, verificou-se que as atividades e avaliações precisam ser elaboradas de forma a instigar o raciocínio e aprendizado significativo, eliminando respostas automáticas ou decoradas, evitando resultados maquiados que não condizem com aos objetivos de aprendizagem do aluno.

Ficou evidente que aprender requer autoria, autorregulação e a realização de atividades cognitivas mais profundas. Quanto mais autoral, menos memorização e mais aprendizado efetivo. Quanto mais autorregulação, menos procrastinação. Quanto mais profundas as atividades cognitivas, mais significativas.

Notas:

${ }^{\mathrm{i}} \mathrm{SciELO}$ https://www.scielo.org BDT http://bdtd.ibict.br/vufind/, ERIC https://www.eric.ed.gov SCIENCE DIRECT https://www.sciencedirect.com PUBMED https://www.ncbi.nlm.nih.gov/pubmed

O levantamento considerou o recorte temporal de 2012 a 2016 e usou para a busca as seguintes palavras-chave: "teorias de aprendizagem"; "estratégias de estudo"; "ensino superior", bem como os equivalentes em língua inglesa "learning theory"; "learning strategies"; "study strategies"; "higher education".

${ }^{\text {i }} 16$ artigos científicos de livre acesso, sendo 6 em língua portuguesa, 3 em língua espanhola e 7 em língua inglesa.

Quadro 2: Relação de publicações identificadas nas bases de dados consultadas.

\begin{tabular}{|l|l|}
\hline $\mathrm{N}^{\mathrm{o}}$ & Artigos \\
\hline 1 & $\begin{array}{l}\text { COSTA, S. G.; ROMERO, S. M. T. Cognitivismo: o que acontece no "interior" das pessoas. Psicologia } \\
\text { Aplicada À Administração, p. 75-103, 2011. }\end{array}$ \\
\hline 2 & $\begin{array}{l}\text { GALVÃO, A.; CÂMARA, J.; JORDÃO, M. Estratégias de aprendizagem: reflexões sobre } \\
\text { universitários. Revista Brasileira de Estudos Pedagógicos, v. 93, n. 235, p. 627-644, 2012. }\end{array}$ \\
\hline 3 & $\begin{array}{l}\text { COSTABILE, A. et al. Metacognitive Components of Students' Difficulties in the First Year of } \\
\text { University. International Journal of Higher Education, v. 2, n. 4, p. 165-171, 2013. }\end{array}$ \\
\hline 4 & DUNLOSKY, J. Strengthening the Student Toolbox. American Educator, v. 37, n. 3, p. 12-21, 2013. \\
\hline
\end{tabular}




\begin{tabular}{|l|l|}
\hline 5 & $\begin{array}{l}\text { FERNÁNDEZ ZALAZAR, D.; NERI, C. Estudiantes universitarios, TICS y aprendizaje. Anuario de } \\
\text { investigaciones, v. 20, n. 1, p. 153-158, 2013. }\end{array}$ \\
\hline 6 & $\begin{array}{l}\text { FULOP, S.; CHATER, N. Editors' introduction: Why formal learning theory matters for cognitive } \\
\text { science. Topics in Cognitive Science, v. 5, n. 1, p. 3-12, 2013. }\end{array}$ \\
\hline 7 & $\begin{array}{l}\text { FURLAN, L. A. Eficacia de una intervención para disminuir la ansiedad frente a los exámenes en } \\
\text { estudiantes universitarios argentinos. Revista Colombiana de Psicología; Vol. 22, no 1 (2013); 75-89 } \\
\text { 2344-8644 0121-5469, v. 22, n. 5000, p. 75-89, 2013. }\end{array}$ \\
\hline 8 & $\begin{array}{l}\text { TEIXEIRA, A. R.; ALLIPRANDINI, P. M. Z. Intervenção no uso de estratégias de aprendizagem diante } \\
\text { de dificuldades de aprendizagem. Psicologia Escolar e Educacional, v. 17, n. 2, p. 279-288, 2013. }\end{array}$ \\
\hline 9 & $\begin{array}{l}\text { CARUTH, G. Learning How to Learn: A Six Point Model for Increasing Student Engagement. } \\
\text { Participatory Educational Research, v. 1, n. 2, p. 1-12, 2014. }\end{array}$ \\
\hline 10 & $\begin{array}{l}\text { GUERRERO, I. R. A. et al. Comparación de estrategias de estudio y autorregulación en universitarios. } \\
\text { Revista Electronica de Investigacion Educativa, v. 16, n. 1, p. 137-148, 2014. }\end{array}$ \\
\hline 11 & $\begin{array}{l}\text { MARTINS, L. B.; ZERBINI, T. Escala de Estratégias de Aprendizagem : evidências de validade em } \\
\text { contexto universitário híbrido. Psico USF, v. 19, n. 2, p. 317-328, 2014. }\end{array}$ \\
\hline 12 & (ROTTHOFF et al., 2014) \\
\hline 13 & $\begin{array}{l}\text { BORUCHOVITCH, E.; DOS SANTOS, A. A. A. Psychometric studies of the learning strategies scale } \\
\text { for university students. Paideia, v. 25, n. 60, p. 19-27, 2015. }\end{array}$ \\
\hline 14 & $\begin{array}{l}\text { DAI, W. et al. Recent Advances in Learning Theory. Computational Intelligence and Neuroscience, } \\
\text { v. 2015, n. 2, p. 2-5, 2015. }\end{array}$ \\
\hline 15 & $\begin{array}{l}\text { RENZULLI, S. J. Using learning strategies to improve the academic performance of university students } \\
\text { on academic probation. NACADA Journal, v. 35, n. 1, p. 29-41, 2015. }\end{array}$ \\
\hline 16 & $\begin{array}{l}\text { SCACCHETTI, F. A. P.; DE OLIVEIRA, K. L.; DA COSTA MOREIRA, A. E. Estratégias de } \\
\text { Aprendizagem no Ensino Técnico Profissional. Learning Strategies in Vocational Technical } \\
\text { Education., v. 20, n. 3, p. 433-446, 2015. }\end{array}$ \\
\hline
\end{tabular}

iii Os novos conhecimentos que se adquirem relacionam-se com o conhecimento prévio que o aluno possui. Ausubel define este conhecimento prévio como "conceito subsunçor" ou simplesmente "subsunçor" (MOREIRA, 1999).

${ }^{\text {iv }}$ Embora Piaget e Vigotsky tenham desenvolvido seus estudos em momentos históricos concomitantes, o contexto geográfico e político não permitiu a aproximação desses investigadores. As publicações das produções científicas do mundo entravam na Rússia czarista, porém a produção dos intelectuais russos não era publicada e divulgada no mundo. Nesse contexto, Vigostky teve acesso aos escritos de Piaget, porém Piaget não teve acesso às produções de Vigostky.

\section{REFERÊNCIAS}

ALVES, L. O. Poluição visual. InfoEscola. 2014. Disponível em: https://www.infoescola.com/meio-ambiente/poluicao-visual/

ALMEIDA, G. P. A aprendizagem significativa de David Paul Ausubel. 20161 vídeo (10 min), son, color. Publicado pelo canal Geraldo Peçanha Almeida. Disponível em: https://www.youtube.com/watch?v=wZzwpF2S1uY.

ANDRADE SILVA, L. D. Educação medicalizada e medicalizante: (in)disciplina e violência. In: BARBOSA, M.V.; GONÇALVES, A. R.; GAYDECZKA, B.; DANTAS, F. B.; BARBOSA, J. B.; FERNANDES, N. M. (org.). A boniteza de ensinar e a identidade do professora na contemporaneidade. São Paulo: Mercado de Letras, 2015. p. 267-288.

AUSUBEL, D. A aprendizagem significativa: a teoria de David Ausubel. 2. ed. São Paulo: Centauro, 2006. 
BARDIN, L. Análise de conteúdo. Lisboa: Edições 70, 2010.

DEMO, P. Metodologia para quem quer aprender.São Paulo: Atlas, 2008.

DUNLOSKY et al. Improving students' searning with effective learning techniques.

Psychological Science in the Public Interest. Vol 14, Issue 1, 2013. Disponível em: http://journals.sagepub.com/doi/pdf/10.1177/1529100612453266

FREIRE, P. Pedagogia do oprimido. Rio de Janeiro: Paz e Terra, 2010.

GAGNÉ, R. Princípios essenciais da aprendizagem para o ensino. Rio de Janeiro: Globo, 1980.

GALVÃO, I. Henri Wallon: uma concepção dialética do desenvolvimento infantil.

Petrópolis: Vozes, 1999.

GALVÃO, A.; CAMARA, J.; JORDÃO, M. Estratégias de aprendizagem: reflexões sobre universitários. Rev. Bras. Estud. Pedagog., Brasília, v. 93, n. 235, p. 627-644, Dec. 2012. Disponível em: http://www.scielo.br/scielo.php?script=sci_arttext\&pid=S2176$\underline{66812012000400006 \& \operatorname{lng}=\mathrm{en} \& \mathrm{nrm}=\mathrm{iso}}$

HAUGEN, C. R. Questionando a neutralidade das estratégias de aprendizagem: uso dos saberes prévios por professores e alunos. Educação e Realidade. v. 40, n. 2, p. 421-442, 2015.

MOREIRA, M. A. Teorias de Aprendizagem. São Paulo: E.P.U, 1999.

PERRENOUD, P. 10 novas competências para ensinar: convite à viagem. Porto alegre: Artmed, 2014.

PIAZZI, P. Inteligência em concursos. São Paulo: Aleph, 2013.

ROGERS, C. Liberdade para aprender. Belo Horizonte: Interlivros, 1973.

SAMPAIO, R. et al.. Autorregulação da aprendizagem e a procrastinação acadêmica em estudantes universitários. Cadernos de Educação, n. 42, p.119-142, 2012.

TEIXEIRA, A. R.; ALLIPRANDINI, P. M. Z. Intervenção no uso de estratégias de aprendizagem diante de dificuldades de aprendizagem. Psicologia Escolar e Educacional, v. 17, n. 2, p. 279-288, 2013.

VIGOTSKY, L. S. A formação social da mente: o desenvolvimento dos processos psicológicos superiores. 6. ed. São Paulo: Martins Fontes, 1998. 